\title{
NEGATIVELY SHAPING THE ASYLUM AGENDA? THE REPRESENTATIONAL STRATEGY AND IMPACT OF A TABLOID NEWS CAMPAIGN
}

\author{
Julian Matthews \\ Department of Media and Communication, University of Leicester, UK.
}

\author{
Andy R. Brown. \\ Department of Media Communication, Bath Spa University, UK.
}

Authors' final version of:

Matthews, J and Brown A.R. 2012. Negatively Shaping the Asylum Agenda? The

Representational Strategy and Impact of a Tabloid News Campaign. Journalism Criticism, Theory and Practice 13(6): 802-817 (DOI: 10.1177/1464884911431386 -

http://jou.sagepub.com/content/13/6/802)

\begin{abstract}
This article examines coverage presented in a news campaign (on asylum and immigration) by the UK tabloid newspaper, the Sun, from January to March 2003. The analysis reveals how tabloid news conventions rather than government definitions or viewpoints frame the character and contours of campaign representations, an observation that throws into sharp relief existing explanations of elite influence or authority skew. This campaign includes portrayals of the asylum seeker as 'the other' or 'folk devil', a moral framework explaining their deviant intentions and actions, as well as expressions of irreverence at elite decisionmaking and government UK asylum policy. Yet it is striking how accompanying tabloid representations of public opinion, featuring consistently through the coverage, offer additional hostility to asylum policy and government officials. The article outlines how such representations and appeals garner the attention of the political elite and elite media on this occasion and develop new concerns over the newspaper's role in negatively shaping the asylum agenda.
\end{abstract}

Keywords: Asylum/immigration, news campaign, news conventions, tabloid news form, tabloid newspapers 


\section{Introduction}

Newspaper campaigns, as now prevalent features of the media landscape, offer coverage that deviates from the dominant norms of journalistic output (Birks, 2010). Rather than report impartially on situations, they package constructed issues and representations of public opinion into a recognisable campaign format, producing these with the firm intention to attract and lobby the attention of the powerful. At the centre of their concern is often the outsider(s) - who is perceived to pose a tangible threat to the order, resources or populace of local communities (Kitzinger, 1999) - be that the paedophile (Cross and Lockyer, 2006), Gypsy (Morris, 2000) or more recently the asylum seeker. The form and frequency of current newspaper campaigns appearing in local journalism and shaped to attract, crystallise and maintain a local readership has been well documented (Aldridge, 2007). Yet, their more recent migration to, and newfound place within, the daily national newspaper (Critcher, 2002) is under-researched. As such, the national newspaper campaign is the subject of this article's analysis which looks specifically at an early campaign produced by the Sun in 2003 that focused on perceived problems with government policy on asylum seekers.

This article discusses the Sun's news campaign in the context of research on the media's reporting of asylum and immigration issues at a time when most European politicians and media outlets were discussing the movement of people, in and through Europe, often in terms of a need for their control (Thompson, 2003). It is perhaps no surprise that these studies describe similar reporting produced against this context, outlining the media's reproduction of negative framing of the issues and those involved in similar ways to past coverage of ethnic minorities (Stratham, 2002). This article seeks to contribute fresh insights to this established literature by examining how the depoliticised characteristics of the tabloid newspaper structure the specific campaign representations. Of interest is how these construct the asylum issue - including the source of the problem and those responsible for its management - for the tabloid reader and whether the irrelevance to political elites common to tabloid coverage appears in such representations. These questions have relevance for the often-presumed relationship between elite perspectives and media coverage offered in media theory. Additionally, the article questions whether campaign representations, focused on political elites, have an impact. Commenting on the campaign's relationship with the 'alternative elite media audience' (Davis, 2003), conceived here as elite media and political elites, the article asks, does the campaign attract elite reaction and, if so, what does this reveal about the importance of tabloid newspapers in the hierarchy of the press?

\section{News campaigns and the asylum issue}

This article discusses a campaign against UK government policy on asylum and immigration developed by a popular UK tabloid newspaper, the Sun. Over two months (from January 2003 to March 2003) the observed coverage reproduced various claims about asylum seekers and the UK asylum system - maintaining a focus that chimes with a long and wellestablished media interest observed by previous research. Immigrants or refugees moving through Europe and into the UK have been the subject of media attention over a long period of time, including early reports in the 1960s and 1970s (Jones, 1971; Seymour-Ure, 1974), later reports in the 1980s and 1990s (Greenslade, 2005; King and Wood, 2001) and beyond, in the UK and EU countries (Campani, 2001; d'Haenens and De Lange, 2001; Van Gorp,

2005). Continuity in the media's approach complements the observed similarities across its coverage. Using a common 'problem framework' to make sense of different issues, news stories, it is argued, reproduce particular frames, myths, oppositions and negative language (Mollard, 2001). 
However, the complexity that exists in some newspaper outputs must be acknowledged when reviewing such general claims. Pertinent aspects, such as the newspapers' news forms, political affiliations and positions in the UK press structure, it is suggested, produce various possibilities and limitations in the production of stories on asylum (KhosraviNik, 2009). Within this, news framing has included, on occasion, humanitarian ideas in descriptions of countries' asylum systems and asylum seekers in broadsheet newspapers other than those with a liberal political focus. Nonetheless, the general direction of political discussion and asylum policy toward controlling entrance to the UK has informed much media discussion and debate (Finney, 2003). There is no escaping the overwhelming evidence of similar media frames in UK newspapers, and beyond, that address the asylum issue from administrative and legal concerns (Nickles, 2007) or, as Horsiti (2007) explains graphically, in terms of issues of 'illegality and control'. There appears to be a blurring of the sharp differences that delineate the economic migrant from the asylum seeker or refugee (Article 19: 2003: 17) in coverage that often stresses the financial expense associated with their illegal actions for government's asylum systems (Coole, 2002). Binary oppositions often structure this coverage, depicting the 'good' and the 'bad' migrant and assisting with the reproduction of the 'bogus asylum seeker' category used in 1990s and beyond (Cohen, 2002; Kaye, 1998).

Prominent discussions of asylum seekers' overt criminal intentions, a finding that is significant in itself, mask a wider embedded presentation of asylum seekers as different from the general UK population, a contrast that is represented in terms of prominent oppositions such 'us' vs 'them' in coverage (Erjavec, 2003). News story language differentiates the newspaper reader from the asylum seeker, presenting the latter often as 'the other' (Baily and Harindranath, 2005), as is found commonly in studies employing discourse and metaphor analysis (e.g. El Refaie, 2001) and even those examining those readers' letters selected and posted by newspapers (e.g. Lynn and Lea, 2003; Richardson and Franklin, 2003) on this topic. Further rhetorical 'strategies of belonging' in coverage address newspaper audiences, emphasising their differences with asylum seekers (Pitcher, 2006: 538). When reflecting on explanations for the character of this coverage, studies predominately point to the influence of a construction of the asylum seeker (Thompson, 2003), produced and used by political elites to gain political capital (Billing and Golding, 1992). It is suggested that government spokespersons' views and ideas influence news story production through their routine presence as news sources or talking heads for the media (Klocker and Dunn, 2003: 71) and feature in stories considered as balanced, as well as those not (Kaye, 1998; Mollard, 2001; Philo and Beattie, 1999).

\section{Asylum, the tabloid and its form}

Against this backdrop, this article examines the representation of asylum in a tabloid news campaign - a combination of topic and newspaper that is discussed with much concern by previous academic work. Studies view tabloid newspapers with particular apprehension because of their presumed reproduction of conservative ideology linked to their ability to influence readership's views and opinions along such lines. On asylum, Kundnani (2001: 48) states, 'the tabloids reflect the state ideology of suspicion and deterrence against asylum seekers'. This news formula, when reproduced, creates, it is suggested, a general background context of tension and fear from which public opinion on this issue is formed (Finney and Peach, 2004) and, according to some, it perpetuates new forms of racism built on cultural difference (Gilroy, 1992). Such claims for direct media effects are often stated but are rarely studied (Hewitt, 2002) however - a criticism that should be applied also to the accepted views on those factors seen to shape tabloid coverage. 
Recent commentaries buck this trend when discussing tabloid newspapers' complex news coverage - in direct contrast to the much-heard criticism of their function as political mouthpieces for elite viewpoints on various issues (Biressi and Nunn, 2008). Rather than reproducing elite politics, the tabloid news agenda, it is argued, is generally depoliticised, favouring within its remit topics of sport over politics, as well as 'human interest' over economic life, the local and immediate over the international and the long term (Sparks, 2000). Political issues appear in tabloid newspapers infrequently on the whole and adopt particular formations at such moments when their newspaper's news values coincide with those of the quality press (Sparks, 1992a: 39). Contrary to the political reporting in broadsheet journalism, their 'political coverage', Sparks (1992a: 41) suggests, offers a focus based on 'immediacy of explanation', which is rooted in 'a direct appeal to personal experience' and often references 'human-nature', 'moral behaviour' and 'individual failings' as explanations for phenomena. Shaped in accordance with its unique form, the political story makes no effort to describe the structures and processes that lie outside of reported experiences. Offered in its place is a tabloid response to the intruding political world with a 'reactionary populism', adds Sparks (1992b) when concluding his overview of this political reporting. Yet, the detailed character and content of tabloid political stories - such as those covering asylum - can be further understood by connecting the tabloid 'genre and subgenre conventions' to particular story representations (Cottle, 1998: 98). This practice can add much-needed detail to Spark's general overview.

Thus, it can be argued that the characteristics of tabloid news form appear essential to understanding the form taken by tabloid political coverage. Cottle (1993: 20-21) defines these in opposition to the conventions of quality newspapers, suggesting their focus on: (1) the private sphere and the moral order rather than public sphere and parliamentary or institutional order; (2) news access given to ordinary people over elites; (3) coverage which seeks to affirm values rather than offer rationalistic information or debate; (4) stories designed with a subjective rather than an objective news epistemology that favours experiential accounts over authoritative opinion or facts; (5) news delivered with a partisan rather than an authoritative mode of address; and (6) stories that offer engaged and immediate, rather than the deliberative and detached, news language and visuals. When combined, these points provide a framework that can be used to explore the construction of political stories of asylum and the wider campaign.

\section{Analysing a tabloid news campaign}

This article explores the formation and impact of a news campaign produced by the national tabloid newspaper the Sun. A newspaper database (Newsbank) was used to complete the sample of coverage after a portion was collected first as part of another research project.

The finalised news sample included 108 newspaper items ${ }^{i}$ that contributed to the newspaper's campaign, collected over a period, defined by the newspaper's announcements of the campaigns' start and end (20 January 2003 and 4 March 2003). At a later point, these data were used to research connections between the campaign coverage and other newspaper output, findings that are introduced shortly. In response to the above discussion, the analysis of campaign stories was directed in line with the following question: how do tabloid news conventions shape the campaign coverage on the asylum issue?

Subgenre analysis ${ }^{\mathrm{ii}}$ was applied to analyse the campaign representations and provide an answer to this question. This approach shares common ground with previous research that has studied the news programmes as genre, including those (1) categorisation studies which describe the formal composition of news programmes (Newbold, 1998) and (2) exchange studies that chart a connection between genre, text and audience, conceived often in terms of 
the reproduction of ideology or hegemony (Hartley, 1980). Yet its interest in how subgenre conventions of the tabloid newspaper shape its political coverage places the work closer to recent developments in news production studies. Recent news production work focuses on the news subgenre as standardised knowledge that is visualised and reproduced by news professionals in the production process (Cottle, 1993) and as a core explanation for the particularised character and inflections that differentiate various news programmes (Harrison, 2000; Matthews, 2010). An understanding that subgenre characteristics shape news content informs this analysis of the campaign coverage. Although it is recognised that the method of textual subgenre analysis will not recover the intentions of news producers (Erjavec and Kovacic, 2009: 152), its application will uncover how representations of asylum, in this case, are ordered and shaped in line with the subgenre conventions of the tabloid newspaper. This project combined the insights from studies of the news coverage of asylum with those on the subgeneric conventions of the tabloid form to produce the following characteristics that were used to structure its analysis:

- Moral and political framework: community/commonsense/common values/us and them/moral discourse:

- Representation of 'others': folk devils, bogus refugees and asylum seekers, spongers, scroungers and devious manipulators, etc.

- Affirmation/celebration of tabloid culture: - irreverence shown to elite figures, authority and other organisations, etc. Use of slang, colloquialisms, puns and humour.

- Public opinion: ordinary voices

\section{Analysis}

Launched on 20 January 2003, the Sun's campaign continued to the early part of March 2003. Over this time, the coverage introduced readers to the campaign issue, explaining the connections with their everyday circumstances and reporting on the ongoing drama's main actors, including asylum seekers, everyday readers and those managing the UK asylum system. These characteristics were presented in line with the subgenre conventions of the Sun, a tabloid.

A constructed commentary on the campaign issue is the backbone of the Sun's campaign coverage. Introduced at significant points over the campaign, this description, written in an expected tabloid form, makes plain what is at stake in this issue. First, it speaks from the position of the moral guardian, defining the issue in terms of normal and the deviant, the boundaries and borders of acceptable behaviour and the 'consensus' being affronted by the 'actions' of individuals (Cohen, 1973; Critcher, 2003; Hall et al., 1978). The process of immigration is simplified and naturalised as a significant problem at these times, defined by the newspaper as a destabilising force acting on a preferred, maintained and appropriate balance between population and resource within the UK. Second, the descriptions address the tabloid reader directly, suggesting the readership's collective experience of UK health and welfare services is being shaped by immigration. Increased immigration, the moral logic of these descriptions reasons, challenges British readers' ideas of 'fairness' (in access to resources) and in practice reproduces their widespread disadvantage as is expressed below: 
IT was no surprise to learn that the UK is the number one destination for asylum seekers. We are seen as a soft touch with our system of benefit handouts and offering housing, healthcare and accommodation to asylum seekers. Often it appears that these immigrants are looked after much better than our own people. The crazy part of it all is that the UK is just a little island with a limited amount of resources. We must become as tough as other nations before the situation grows completely out of control. (The Sun, 25 March 2003)

This coverage addresses its community of readers 'from the perspective of the threat of the outsider' (Conboy, 2002: 157). Situated within these accounts is a constructed representation of the immigrant, devised with the purpose to heighten the impending sense of menace. As significant to descriptions of the campaign issue and the various stories that surround them, the tabloid construction of the asylum seeker appears here in a unified way in the form of abstract group descriptions that avoid case study details of actual individuals. Helping to justify campaign concerns, these bedrock representations emerge in a form similar to this example:

EVERY week 1500 illegal immigrants swarm into Britain falsely claiming benefits at the expense of hard working taxpayers. They take advantage of a system that FAILS to stop fraudulent claimants getting in - then FAILS to eject them once they are here. The Sun supports immigration but the UK has become a doormat for the world to wipe its feet on. Britain is held up to ridicule because it takes the MOST asylum seekers of any European nation and gives the most GENEROUS HANDOUTS. (The Sun, 20 January 2003)

As revealed in the above, this construction stamps the immigrant with a unified mentality and goal, linking such attributes to its explanation of the uncontrolled 'swarms', 'floods' and 'waves' of illegal immigration. It is stressed how the likely financial benefits gained from UK residence (described as its welfare and health system) compound immigrants' desire to enter the UK over other countries. Other concerns associated with illegal immigration mark the campaign coverage. 'Unchecked' immigrants and immigration produce concerns for UK security, the campaign suggests, and this places a focus of concern on immigrants' culture, religious beliefs specifically, as drivers for criminal intentions and actions. Deviant asylum seekers, as indistinguishable from genuine asylum seekers, are linked with potential acts of terrorism in ongoing story themes across the coverage, similar to the following: 'The terrorist time bomb has been ticking for years. Known psychopaths hide among hundreds of thousands of illegal immigrants. But all Tony Blair and David Blunkett do is bury their heads in the sand ...' (The Sun, 22 January 2003).

Connecting illegal asylum seekers with terrorist organisations and criminal acts personalises the issue to the readership, providing opportunities to single out particular instances and circumstances for further negative attention within the coverage. Stories suggest some asylum seekers hold covert memberships and allegiances to terrorist organisations and, when able, they plan and carry out terrorist plots while living in the UK. The suspects in the ongoing trial over alleged production of the poison Ricin in January 2003, for example, became ongoing subjects in the campaign, following the newspaper's original statement that the reprimanded were 'asylum seekers, living on benefits ... with their accommodation paid for by taxpayers' (The Sun, 30 January 2003). Other coverage includes select examples of asylum seekers, such as the presence of Taliban soldiers in the UK. A popular theme in the coverage of the dangerous enemy within the UK is illustrated by the headline 'You pay for Taliban thug to live here - War on Terror' and its corresponding story that explains how a Taliban solider, '... who almost certainly served alongside al-Qa'ida henchmen, fighting British soldiers in Afghanistan [...] is staying in the UK at taxpayers' expense to protect his "human rights" (The Sun, 20 January 2003). In addition to immigrants, authority figures feature prominently in the campaign. 
Authority figures appear commonly in news coverage of political issues. Yet, their presence as subjects for marked displays of irreverence is an integral feature of tabloid newspapers' general affirmation or celebration of their culture and this campaign. As Connell (1992) describes, tabloid news coverage condemns members of the powerful or celebrity class when seen to transgress 'acceptable' boundaries.

In this case, the Sun's coverage condemns authority figures involved with asylum and immigration policy, directing specific lines of criticism to senior government individuals including the (then) Prime Minister, Tony Blair, and the (then) Home Secretary, David Blunkett. Tony Blair is lampooned throughout the coverage on account of being too far removed from people's everyday experience of the 'asylum crisis', and his thoughts as out of touch with the wishes of ' 10 million Sun readers ... who probably voted for you last time round [...] now, feel betrayed by you' (The Sun, 28 January 2003). Nonetheless, the (then) Home Secretary, described as directly responsible for and able to rectify 'the asylum problem' in the campaign, is placed under increasing scrutiny. A prominent theme is his psychological health ${ }^{\mathrm{iii}}$ expressed in coverage which introduces the official as under strain from, and unable to manage, an asylum system that is 'in crisis'. After the Home Secretary publicly criticises the newspaper's campaign (Kampfner, 2003), the examination intensifies by ridiculing his so-called speeches as 'astonishing rants' before criticising the Home Secretary's and UK government's 'inability' to accept, as important and rational, thousands of newspaper readers' support for the newspaper's campaign ${ }^{\text {iv }}$.

Additionally, the tabloid use of humour to trivialise the serious news issue features prominently in the campaign. As Cottle (1993) explains, tabloid newspapers use puns, slang, stereotypes, caricatures and exaggerated personalisations as well as manipulate images and concoct attention-grabbing scenarios and 'fake-documentary' photo-shoots to heighten sensation and provide reader entertainment. The following story, situated within a longrunning commentary on the radical Muslim cleric Abu Hamza, helps to illustrate how such techniques feature in one instance.

The theme of the 'dangerous immigrant' within the UK develops prominently in the general campaign coverage as has been outlined. Although often expressed plainly, this is also exhibited with traditional tabloid 'fun', with the Sun on this occasion using photo stunts to introduce its case against Abu Hamza, who is claimed to be actively encouraging terrorism and preaching religious hatred. At the forefront of coverage is the newspaper's attempt to encourage the radical cleric ${ }^{v}$ to leave the UK. One headline describes this as 'HOOK GETS A ONE WAY SUN TICKET' (The Sun, 22 January 2003). Not only poking fun at Hamza in accordance with his disability (an artificial hand), the story content under the subheading 'We buy Hamza $£ 375$ trip home’ outlines the newspaper's efforts to deliver a purchased one-way aeroplane ticket (which is pictured as an enlarged insert) to the cleric's front door. Referring to the newspaper's headline the previous day, inviting Hamza to 'SLING YOUR HOOK' (The Sun, 21 January 2003), the account makes clear 'public demands' for 'this fanatic' to leave the UK are 'reaching a crescendo'. Issued throughout the campaign, these demands, made on behalf of the public, are included to justify the newspaper's campaign against the cleric. What is more, representations of public support for the campaign, shaped according to tabloid news conventions, play a prominent role in the campaign generally (see Table.1). 
Table 1: Representation of Campaign Support

\begin{tabular}{ll}
\hline Date & Petition Numbers \\
\hline $20 / 01 / 03$ & Campaign lunch \\
$23 / 01 / 03$ & 50,000 \\
$24 / 01 / 03$ & 100,000 \\
$27 / 01 / 03$ & 230,000 \\
$28 / 01 / 03$ & 300.000 \\
$29 / 01 / 03$ & 385,000 \\
$30 / 01 / 03$ & 440,000 \\
$31 / 01 / 03$ & 510,000 \\
$04 / 02 / 03$ & 550,000 \\
$05 / 02 / 03$ & 568,000 \\
$08 / 02 / 03$ & 600,000 \\
$11 / 02 / 03$ & 605,000 \\
$1 / 03 / 03$ & $1,000,039$ \\
\hline
\end{tabular}

Rather than gauge public reaction or balance various opinions in impartial manner, the coverage includes representations of public opinion to demonstrate favourable reaction to the campaign. Numbers of returned newspaper petition coupons containing readers' signatures are one form that is used. As measured in this instance by the return of these coupons, claims of support are included frequently in the coverage (see Table.1), starting with early descriptive examples such as: 'Thousands of angry Sun readers rushed to join our campaign to save Britain from asylum madness' (The Sun, 21 January 2003). Thereafter, numerical indicators of campaign support appear alongside its challenges to government policy and politicians. A mock-up letter to the then Prime Minster headed 'Dear Mr. Blair' (The Sun, 28 January 2003), introduced early in the campaign, claims that 300,000 readers returned coupons in support and warns that individuals in copying and passing these 'around their neighbourhoods, workplaces, shops and pubs' will increase the total number to 400,000 . Later, an enlarged figure features in a story subheading ' 385,000 SAY NO' that opines how 'Sack loads of coupons arrived at our offices urging the Government to act over the tide of bogus refugees' (The Sun, 29 January 2003). Additionally, the level of support (as measured in the return of coupons) features in accompanying news photographs. A case in point has a photo 'set-up' of Sun journalist accompanied by three Sun readers, delivering '40 more sacks of petition letters to No.10' (although only 10 sacks are visible). An included quote from a reader stating that 'now the Government must sit up and listen' is followed by the statement that the newspaper has received 586,844 responses from readers. On 1 March 2003, the newspaper declares how ' 1 million readers' have supported the campaign to 'get tough on asylum cheats'.

The introduction of vox pops interviews with Sun readers over this time is another way that the newspaper demonstrates support for its campaign. Peppering the coverage, these extracts follow a similar presentation that includes interviewees' name and location (such as 'Julie Purdham, of Reading, Berks; Rob Jones of Manchester; James Coster from South London') accompanied by their edited opinion statements, organised to show continuity with the newspaper's opinions. Interviewees' comments describe worries over illegal asylum seeking and issues with incompetent officials and government inaction consistently over the campaign. A pertinent representative case comments: 'Enough is enough. The vast majority of the British public is sick to the back teeth of the ridiculous situation' (The Sun, 6 February 2003). Another clarifies the source of the problem with the line: 'When is Blair and Blunkett going to stop these parasites from entering our country? The only reason they are coming here is to get as many free handouts as possible' (The Sun, 23 January 2003). Likewise, the 
voices of Britain's ethnic minorities appear prominently as stalwart campaign supporters in these sections. As a case of two British Asian newsagents illustrates, these voices reproduce the newspaper's 'common sense' view on asylum, explaining on this occasion that 'The Government has been too soft on this issue. Are these people genuine asylum seekers or are they bogus? I totally agree with the Sun's campaign' (The Sun, 22 February 2003). Other British Asian citizens voice indignation about 'bogus asylum seekers' in these sections, expressed in personal observation or anecdote. A 21-year-old British Asian student, for example, is quoted as saying, 'From what I can see these so-called asylum seekers just get money given to them - whereas I've got to work for mine.' A 57-year-old British Asian taxi driver offers the following: 'I know one English lady who applied for council housing and had to wait six months but asylum seekers get houses straight away without giving any reason.' Later panelled sections designed to demonstrate the representativeness of the presented voices and opinions emerge, with the chosen interviewees ordered by their differences in religious faith, marital status, age, occupation and length of residence in Britain. In one example, five married couples are introduced as responding to pre-set questions on the asylum issue, providing similar answers to each other and the concerns of the campaign. In answering the question 'Are you worried about the influx of bogus asylum seekers?', the following five responses appear:

Couple one: 'The number of bogus asylum seekers being allowed into Britain is a worry because it amounts to a drain on resources.'

Couple two: 'We are very worried that tens of thousands of bogus asylum seekers are being allowed into Britain.'

Couple three: 'Britain is very tolerant of immigrants [...] But people are beginning to feel the country is letting too many in.'

Couple four: 'The Government is failing to deal with the issue of people coming here from all over the world. They are getting in too easily and it is taking its toll on the country's resources.'

Couple five: 'if people are entering England who don't generally need our help then there's obviously a big problem.' (The Sun, 1 February 2003)

This discussion has outlined how the newspaper's representational strategy owes its character to tabloid news conventions, including instances of public opinion shaped to voice support for campaign objectives. The next section discusses the possible impacts of these representations.

\section{Direct and indirect campaign impacts}

Previous studies have addressed the impacts of news campaigns, including what appears to be the growing attentiveness of other newspaper outlets along with newspaper readerships. Work on regional newspapers suggests the ability of their campaigns to move beyond the readership and set the terms of wider debate in other media on such occasions (Cross and Lockyer, 2006), including their shaping of the nature of elite media discourse (Murphy, 1976). Critcher's (2003) study of the British middle-market newspaper the Daily Mail confirms the palpable impact of campaign coverage on elite media agendas. Stretching the ideas of those influenced by campaign coverage to include elite policy representatives is Kaye (1998: 79), who suggests these individuals 'may be more influenced by tabloid press coverage than previously thought, if only because of their sensitivity to its potential impact on voter's attitudes'. Taken together, this small literature recognises newspapers' agency to 
speak directly to the 'interests' of elites (political and media) from time to time, but discusses too generally how such coverage achieves legitimacy and how influence is secured in the first place. We suggest an empirical analysis of the particularised impacts of campaign coverage may offer clues as to its potential influence.

As observed, campaigns can attract the interest of elite and other media agendas on occasion, but the question remains, is this case with the Sun's campaign? Our preliminary research suggests the answer is yes and that the campaign impacts can be characterised as 'direct' and 'indirect'. A direct impact is defined as the ability to draw the attention and comments (on its character) of a political elite representative, similar to that of the News of the World's campaign for Sarah's Law where the (then) Home Secretary responded directly to the newspaper concerns. In the case of the Sun's campaign, David Blunkett (the then Home Secretary) criticised its character when writing in the New Statesman and on several other occasions. This elite attention and commentary continued in an interview as part of a Sun article featuring at the end of the campaign, where the (then) Home Secretary suggested that the newspaper was correct and appropriate to raise public concerns over the issue. The significance of this and the criticisms raised about the forthright, independent and antagonistic nature of coverage are discussed in the conclusion.

A second and arguably direct influence is observed by broadsheet media's explicit references to the campaign. By analysing press coverage, we find that the Sun's campaign attracts the attention of other newspapers on several occasions, and further that the flavour of recorded coverage follows the newspapers' political stance. Although The Independent and The Telegraph give passing reference in their pages, The Times, by contrast, comments on the legitimate nature of the campaign several times. After poking fun at how campaign vouchers arriving at the Sun's offices increases pressure placed on postal workers (The Times, 31 January 2003), the paper offers a more serious commentary. In an article 'It's not just fearmongering, the system is a mess ...' (The Times, 28 January 2003), The Times acknowledges some exaggerated campaign features before giving credence to the public perceptions it represents, suggesting the public are aware that the asylum system 'is a bureaucratic mess'. Added to this, it describes astonishment at the attack on the campaign coverage by the (then) Home Secretary, David Blunkett, in an article entitled 'David Vs. Rebekah: It'll be the Sun wot wins it' (The Times, 29 January 2003). A later story (The Times, 31 January 2003), offers a platform for the Sun columnist, Richard Littlejohn, to justify the campaign and his own stance on the issue.

By contrast, the liberal press offer critical commentary on the coverage. On the opening day of the Sun campaign, The Guardian, for example, claims the 'rightwing press has used the death of Detective Constable Stephen Oake ${ }^{\mathrm{vi}}[\ldots]$ to launch fierce attacks on the government's asylum and immigration policies' (The Guardian, 20 January 2003). By the end of the campaign's first week, the paper adds: 'Press whips up asylum terror' (The Guardian, 24 January 2003). By the end of the month, the paper makes specific reference to the Sun campaign, when describing the 'asylum mania of the rightwing press' (The Guardian, 31 January 2003). But this hostile coverage amounts to about a third of the total; the other types of coverage conveyed the position of the government, and its responses to the tabloid agenda, while the remaining items attempted to focus on 'events' and policy debates over the issue.

\section{Inter-media agenda setting: Volume and 'up-spill'?}

Inter-media agenda setting can also be discussed in this instance. An 'up-spill' - movement of an issue through the established structure of the UK press from popular (tabloid) to elite (broadsheet) press - should be considered as an indirect impact of the Sun's campaign. 
Although similar to the 'spill-over effects' witnessed from alternative to established media by Mathes and Pfetsch (1991), the concept recognises the structuration of the UK press (positioned in accordance with their cultural influence) and the legitimacy that issues gain by travelling upwards and entering upper news fora. This description is different to the movement of issues from local to national press documented previously (Aldridge, 2003), as it focuses on the inter-relationship between popular and elite national newspapers in direct contrast to other models of elite media inter-media agenda setting (see Schlesinger and Tumber, 1991).

When examining this coverage alongside Critcher's (2002) observations of the News of the World campaign (Sarah's Law) that created a similar impact, comparisons emerge in, for example, first, the nature of the coverage and, second, the importance of volume of coverage for the movement of the issue. The direct populism of the campaign - particularly its representation of 'public opinion' - mirrors the campaigning for Sarah's Law (a call for the publication of a paedophile register) in the News of the World. In the latter case, Critcher (2002) suggests that key to the escalation of that issue was the entry of other papers into that debate, 'producing a coherent media, rather than merely tabloid, agenda' (2002: 530). Volume of newspaper coverage (comparable in character) appears then as an important catalyst for the upward movement of issues through the structure of the press. In practical terms, the presence of competitive editorialising taking place within down and mid-market tabloids, in these instances, creates the impression of a volume of coverage.

Due to the limited space here, the following can only provide a brief comment on the amounts of coverage across newspapers. At this time we can observe editorialising occurring across the (up- and down-market) tabloid newspapers, producing a concentrated volume of critical coverage on asylum that can be compared with broadsheet newspaper coverage. Over the campaign, for example, the Sun includes 108 articles framing asylum as in crisis, the News of the World (weekly) has 24, The Express 128 and the Daily Mail 67. Over the same two-month period, UK broadsheet newspapers discuss the asylum issue (either as in crisis or as exaggerated to be seen as so) within a significant number of articles: the issue appears in 67 articles in The Telegraph, 57 in The Times, 50 in The Independent and 75 in The Guardian. As we would expect, a number of events structure the combined coverage, including: the death of PC Oake; the opening of a new centre for asylum seekers (Sangatte, Calais) on 14 January; the BNP by-election victory in Calderdale on 25 January; the deportation of Abu Hamza on 26 February; and announcements by MPs. Nonetheless, the majority of newspapers engage collectively with the asylum issue as in 'crisis', often criticising government policy and reviewing government ministers' announcements along these lines. Echoing the tabloid agenda, these broadsheets appear as influenced not directly in terms of content, but in terms of topic. In reinterpreting Cohen's (1963) phrase to explain these moments of inter-media agenda setting, we can suggest that, when collectively reporting on an issue, the up- and down-market tabloids don't tell the broadsheets what to think but perhaps what to think about on occasions. A tentative explanation for this process operating at this time is that there is an 'up-spill' of coverage towards the up-market papers.

\section{Conclusion}

This study of the Sun's coverage has produced insights into the formation and impact of a newspaper campaign. Its account has exposed how the tabloid newspaper performs as a claims maker, producing coverage that establishes, legitimates and demonstrates the UK immigration system as in crisis. Being a newspaper, as opposed to a campaigning group, allows the Sun to talk directly to an established readership as a community affected providing negative comments on the immigration system, those officials managing its 
operations and the asylum seekers seeking refuge. Stark references made throughout the campaign to 'bogus asylum seekers' as either economic migrants or dangerous enemies within the UK - preaching and/or plotting terrorism - resonate strongly with the findings of existing studies on similar news coverage. Nonetheless, the structures of coverage captured in this holistic analysis reveal the significance of tabloid conventions in building the newspaper's account.

Subgenre text analysis has uncovered a blueprint underpinning the campaign representations, offering insights into its complex tabloid political stories. The applied tabloid moral or political perspective, for example, expressed asylum seekers' impact on the everyday experiences and sense of 'fairness' of the community of readers. Its engrained antagonistic stance to governing elites appeared in the campaign's irreverent attitude to relevant political figures. Aspects of tabloid 'fun and spectacle' were used to ridicule other key actors as part of the constructed problem. Representations of public opinion devised to reflect tabloid conventions also contributed to this coverage by voicing support for campaign aims and condemnation for those involved in the 'asylum crisis'. Combined, these aspects have demonstrated how depoliticised tabloid news conventions become repoliticised to express the campaign aims. As a result, the coverage presented a sustained criticism on government policy and actions, an observation which helps to rethink theoretical assumptions of the power of government-produced definitions on news story production generally. Clearly, the tabloid newspaper is not a conduit for government views in this case.

Tabloid conventions are used in this case to communicate a conservative political stance on immigration and asylum, a finding that is beyond the evidence base of this article to explain. However, placing the campaign representations that communicate such politics alongside other elite discussion of the asylum issue does uncover other important relationships. Reactions to the Sun's campaign by elite policy makers and those newspapers occupying elite positions in the press structure demonstrate campaign 'impacts' similar to those outlined by the wider literature. Evidently, news campaigns do attract elite attention and comment, expressed through direct and indirect means. In this case, the latter was demonstrated by a suggested 'up-spill' of the asylum issue into the elite newspaper agendas created by campaign representations coinciding with other tabloid and mid-market coverage on the issue to produce a coherent media agenda. These impacts and operations explain one way that the constructed issue of 'asylum as in crisis' gains legitimacy in the press at this time. On these occasions, observed interconnectivity between newspapers and elite audiences signals the importance of national news campaigns for our future thinking on the nature of issue politics and theories of the press. Wielding their news campaigns, tabloid newspapers spark new concerns over their role in negatively shaping the asylum agenda as well as other issues. 


\section{References}

Article 19 (2003) What's the story? Results from research into media coverage of refugees and asylum seekers in the UK. Article 19, London.

Aldridge M (2003) The ties that divide: Regional press campaigns, community and populism. Media, Culture \& Society 25(3): 491-509.

Aldridge M (2007) Understanding the Local Media. Maidenhead: Open University Press.

Baker P, Gabrielatos C, Khosravinik M, Krzyzanowski M, McEnery T and Wodak R (2008) A useful methodological synergy? Combining critical discourse analysis and corpus linguistics to examine discourses of refugees and asylum seekers in the UK press. Discourse \& Society 19(3): 273-305.

Baily OG and Harindranath R (2005) Racialized 'othering': The representation of asylum seekers in news media. In: Allen S (ed.) Journalism: Critical Issues. Maidenhead: Open University Press.

Billing M and Golding P (1992) Debates: Did the race card tip the balance? News Community 19(1): 161-163.

Birks J (2010) Press protest and publics: The agency of publics in newspaper campaigns. Discourse \& Communication 4(1): 57-67.

Biressi A and Nunn H (eds) (2008) The Tabloid Culture Reader. Maidenhead: Open University Press.

Campani G (2001) Migrants and media: The Italian case. In: King R and Wood N Media and Migration. London: Routledge.

Cohen BC (1963) The Press and Foreign Policy. Princeton, NJ: Princeton University Press.

Cohen S (1973) Folk Devils and Moral Panics: The Creation of Mods and Rockers. London: Paladin Press.

Cohen S (2002) Folk Devils and Moral Panics, 3rd edn. London: Routledge.

Conboy M (2002) The Press and Popular Culture. London: SAGE.

Coole C (2002) A warm welcome? Scottish and UK media reporting of an asylum-seeking murder. Media Culture \& Society 24: 839-852.

Connell I (1992) Tales of tellyland: The popular press and television in the UK. In: Dahlgren $\mathrm{P}$ and Sparks C (eds) Communication and Citizenship: Journalism and the Public Sphere in the New Media Age. London: Routledge.

Cottle S (1993) Taking the popular seriously: Towards a typology for the analysis of the tabloid press. Social Science Teacher 22(3): 20-23.

Cottle S (1999) Ethnic minorities and the British news media: Explaining (mis)representation. In: Stokes J and Reading A (eds) The Media in Britain: Current Debates and Developments. London: Palgrave, pp.191-200.

Critcher C (2002) Media, government and moral panic: Paedophilia in the British press 2000-1. Journalism Studies 3(4): 521-535.

Critcher C (2003) Moral Panics and the Media. Buckingham: Open University Press.

Cross S and Lockyer S (2006) Dynamics of partisan journalism: Journalist-source relations in the context of a local newspaper's anti-paedophile housing agenda. Journalism Studies 7(2): 274-291.

Davis A (2003) Whither mass media and power? Evidence for a critical elite theory alternative. Media, Culture \& Society 25(5): 669-690.

D'Haenens L and De Lange M (2001) Framing of asylum seekers in Dutch regional newspapers. Media, Culture \& Society 23(6): 847-866.

El Refaie E (2001) Metaphors we discriminate by: Naturalised themes in Austrian newspaper articles about asylum seekers. Journal of Sociolinguistics 5(3): 352-371 
Erjavec K (2003) Media construction of identity through moral panics: Discourses of immigration in Slovenia. Journal of Ethnic and Migration Studies 29(1): 83-101.

Erjavec K and Kovacic MP (2009) A discursive approach to genre: Mobi news. European Journal of Communication 24(2): 147-164.

Finney N (2003) The Challenge of Reporting Refugees and Asylum Seekers. Bristol: Presswise/ICAR.

Finney N and Peach E (2004) Attitudes towards Asylum Seekers, Refugees and other Immigrants: A Literature Review for the Commission for Racial Equality. London: Commission for Racial Equality.

Gilroy P (1992) The end of antiracism. In: Donald J and Rattansi A (eds) Race, Culture and Difference. London: SAGE.

Greenslade R (2005) Seeking Scapegoats: The Coverage of Asylum in the UK Press. London: Institute for Public Policy Research.

Hall S, Critcher C, Jefferson T, Clarke J and Roberts B (1978) Policing the Crisis. London: Macmillan.

Harrison J (2000) Terrestrial TV News in Britain: The Culture of Production. Manchester: Manchester University Press.

Hartley J (1980) Understanding News. London: Routledge.

Hewitt RL (2002) Asylum Seeker Dispersal and Community Relations - An Analysis of Development Strategies. London: Goldsmith's College, University of London.

Horsti K (2007) Asylum seekers in the news: Frames of illegality and control. Observatorio 1(1): $145-161$.

Jones C (1971) Immigrants and the news. In: Jones C Race and the Press. London: Runnymede Trust.

Kampfner J (2003) Interview: David Blunkett. New Statesman, 27 January.

Kaye R (1998) Redefining the refugee: The media portrayal of asylum seekers. In: Koser K and Lutz H (eds) The New Migration in Europe: Social Constructions and Social Realities. New York: St Martin's Press.

KhosraviNik M (2009) The representation of refuges, asylum seekers and immigrants in British newspapers during the Balkan conflict (1999) and the British general election (2005). Discourse \& Society 20(4): 277-498.

King R and Wood N (eds) (2001) Media and Migration: Constructions of Mobility and Difference. London: Routledge.

Kitzinger (1999) The ultimate neighbour from hell? Stranger danger and the media framing of paedophiles. In: Franklin B (ed.) Social Policy, the Media and Misrepresentation. London: Routledge.

Klocker N and Dunn KM (2003) Who's driving the asylum debate? Newspaper and government representations of asylum seekers. Media International Australia 109: 71-92.

Kundnani A (2001) In a foreign land: The new popular racism. Race and Class 43(2): 41-60.

Lynn N and Lea S (2003) A phantom menace and the news apartheid: The construction of asylum seekers in the United Kingdom. Discourse \& Society 14(4): 425-452.

Mathes R and Pfetsch B (1991) The role of the alternative press in the agenda-building process: Spill-over effects and media opinion leadership. European Journal of Communication 6(1): 33-62.

Matthews J (2010) Producing Serious News for Citizen Children. A Study of the BBC's Children's Program Newsround. New York: Edwin Mellen Press.

Mollard C (2001) Asylum: The Truth behind the Headlines. Oxford: Oxfam.

Morris R (2000) Gypsies, travellers and the media: Press regulation and racism in the UK. Communications Law 5(6): 21-219.

Murphy D (1976) The Silent Watchdog: The Press in Local Politics. London: Constable. 
Newbold C (1998) Analysing the moving image: Genre. In: Hansen A, Cottle S, Negrine R and Newbold C (eds) Mass Communication Research Methods. London: Macmillan.

Nickles HC (2007) Framing asylum discourse in Luxembourg. Journal of Refugee Studies 20(1): 38-59.

Philo G and Beattie L (1999) Race, migration and media. In: Philo G (ed.) Message Received: Glasgow Media Group Research 1993-98. Essex: Longman.

Pitcher B (2006) 'Are you thinking what we're thinking?' Immigration, multiculturalism and the disavowal of racism in the run-up to the 2005 British general election. Social Semiotics 16(4): 535-551.

Richardson JE and Franklin B (2003) 'Dear editor': Race, readers' letters and the local press. Political Quarterly 74(2): 184-192.

Schlesinger P and Tumber H (1991) Reporting Crime: The Media Politics of Criminal Justice. Oxford: Clarendon Press.

Sparks C (1992a) The popular press and political democracy. In: Scannell P, Schlesinger P and Sparks C (eds) Culture and Power: A Media Culture \& Society Reader. London: SAGE.

Sparks C (1992b) Popular journalism: Theories and practice. In: Dahlgren P and Sparks C (eds) Journalism and Popular Culture. London: SAGE.

Sparks C (2000) Introduction: The panic over tabloid news. In: Sparks C and Tulloch J (eds) Tabloid Tales: Global Debates over Media Standards. Oxford: Rowman \& Littlefield.

Stratham P (2002) United Kingdom. In: European Monitoring Centre on Racism and Xenophobia (EUMC) (ed.) Racism and Cultural Diversity in the Mass Media. Vienna: EUMC.

Thompson M (2003) Images of Sangatte: Political representations of asylum seeking in France and the UK. Available at: http://www.sussex.ac.uk/migration/publications/workingpapers

Van Gorp B (2005) Where is the frame? Victims and intruders in the Belgian press coverage of the asylum issue. European Journal of Communication 20(1): 484-507.

\footnotetext{
${ }^{\mathrm{i}}$ All stories that adopted the topic of asylum or immigration as their main theme and emerged in the confines of the newspaper's campaign (timing as defined by the newspaper itself) were included in the news sample.

ii Subgenre textual analysis provides a number of benefits over other textual methods and approaches. Its application can create an insight into the context that shapes news representations, revealing a determining level (the subgenre) that is often obscured by the focus critical discourse analysis places on social relations, distribution of power and dominant values and ideas (e.g. Baker et al., 2008). When applied, this recovers the distinctive subgenre conventions (Cottle, 1999) that journalists use to shape and order stories, which are so often overlooked by traditional content methods such as discourse and content analysis. Despite uncovering valuable insights into the recurring story themes, frames and lexicons used in news stories with the application of traditional methods, previous studies remain myopic as to the principles that organise particular coverage in line with tabloid news

iii The article 'You all right Dave? Asylum madness' (The Sun, 28 January 2003), for example, reads as 'The Sun fears for the Home Secretary's sanity. CONCERN was raised last night over the sanity of David Blunkett after he launched an astonishing rant against the SUN'.

iv An article entitled 'We're not racists, Mr Blunkett, just terrified for our children's health' (The Sun, 28 January 2003) is a good example, where the Home Secretary's views are criticized, allowing the newspaper to reaffirm its case against the asylum system and government policy.

${ }^{v}$ At this time, Abu Hamza was a radical cleric resident at the Finsbury Park Mosque, London.

${ }^{v i}$ DC Stephen Oake was a detective who was fatally stabbed when he attempted, along with members of the Greater Manchester Police, to detain an individual under the Anti-Terrorism, Crime and Security Act 2001 in Manchester, 14 January 2003.
} 